\title{
POR EL LABERINTO DE LA DIDÁCTICA EN FILOSOFÍA
}

\author{
Gabriel Benavides Rincón* \\ Universidad Pedagógica Nacional
}

\begin{abstract}
La relación entre la escuela y el significado debería ser considerada como algo inviolable. Alli donde surge el significado, allí existe la educación.

M. Lipman
\end{abstract}

\section{Resumen}

La didáctica en filosofía es compleja y con muchos puntos de enfoque, por esta razón metafóricamente se la compara con un laberinto que tiene que resolver aspectos sicológicos sobre las condiciones cognoscitivas que tiene que tomar en cuanta los prejuicios; el espacio del saber propiamente dicho en el contenido de las ideas filosóficas; en otro conjunto las dudas y las crisis existenciales de los estudiantes; y finalmente, el poder del profesor con los sistemas de evaluación.

Palabras clave: didáctica de la filosofía, pedagogía y filosofía.

\section{Abstract}

\section{Through the Labyrinth of Didactics for Philosophy.}

Didactics in philosophy is complex and possesses many focal points; for this reason it is metaphorically compared to a labyrinth that takes into account the following subsets of interest: psychological aspects over cognitive conditions, taking into account existing prejudice; the space of knowing itself in the content of philosophical ideas; the doubts and existential crises of the students; and finally, the teacher's power when deciding on an evaluation system.

KEY WORDS: didactics of philosophy, pedagogy and philosophy

\section{INTRODUCCIÓN}

\footnotetext{
* Licenciado en Filosofía. Magíster en educación, U. de los Andes. Docente del programa Educación Infantil. gaberin@yahoo.com
} 
Para este artículo utilizaré la figura del laberinto como imagen y metáfora de la didáctica en el área de la filosofía. Inicialmente me serviré de la interpretación que hace el profesor Páez Casadiegos ${ }^{1}$ del laberinto, cuando comenta que hay al menos cuatro espacios metafóricos: el espacio psicológico, el espacio del saber, el espacio extático y el espacio del poder.

El espacio psicológico "es un espacio escondido, oscuro y peligroso", y en la didáctica se puede asociar con las imágenes (más bien con los prejuicios) que los estudiantes hacen de la clase de filosofía; presienten que puede tratarse de un espacio interesante o, al menos, diferente, pero, como lo comentaremos más adelante, suele suceder que la única referencia de la clase para los estudiantes es el docente, lo demás es algo misterioso para ellos.

El espacio del saber hace alusión a "la existencia de una espacialidad oculta, oscura o compleja del saber"3; si bien los estudiantes tienen una idea previa de lo que consiste la filosofía, es necesario que ellos crucen "el umbral epistémico que conduce, mediante un salto o una osada penetración, a un espacio de descubrimiento, inseguro, desconocido y atemorizante"4; es decir, que de sus ideas previas han de pasar no sólo al conocimiento del corpus filosófico, sino ante todo al descubrimiento de su propio pensamiento, de un pensamiento que puede llegar a ser de orden superior; que para los estudiantes representa esa habilidad oculta que al iniciar los cursos creen que no poseen.

El tercer espacio es el extático: "es un sitio de iniciación o peregrinaje simbólico. Allí reposan las esperanzas",; es el lugar sagrado donde se encuentran las expectativas del estudiante (más que las del profesor), sobre todo los más jóvenes, quienes tienen la ilusión de encontrar en la clase de filosofía un espacio para sus grandes dudas, sus preguntas existenciales y hasta para sus irreverencias. "¿Qué hay en la filosofía que puede resultar especialmente atractivo para los adolescentes? ¿Es posible que sea lo mismo que les hace sentirse traicionados cuando no reciben aquello que la filosofía parece prometerles?"6.

Y finalmente está el espacio del poder, que "se encuentra en recintos o zonas restringidas al público", ; es un lugar que se debe controlar, podría decirse que usualmente le pertenece más al docente, él guarda -a veces como un tesoro- el diseño de su curso, la secuencialidad de los temas, la didáctica que utilizará en el aula y, sobre todo, guarda con celo sigiloso el poder que le otorga la evaluación.

Otro referente bibliográfico básico para esta exposición lo constituye el trabajo doctoral de Alejandro Sarbach, sobre la didáctica de la filosofía; el autor realiza su investigación interrogándose si “¿Los profesores de filosofía debemos hacer hincapié en la transmisión de contenidos o en el aprendizaje de procedimientos gnoseológicos? O si ¿La comprensión de contenidos es una finalidad en sí misma o son herramientas para desarrollar estos

\footnotetext{
${ }^{1}$ Yidy Páez Casadiegos. "El minotauro en su laberinto”. Aposta. Revista de ciencias sociales n. ${ }^{\circ}$. Obra finalista en el 1. ${ }^{\text {er }}$ Certamen de Ensayo Filosófico del Ciberespacio 2003. 34 p.

2 Ibídem, p. 9.

${ }^{3}$ Ibídem, p. 10.

${ }^{4}$ Ibídem.

${ }^{5}$ Ibídem, p. 11.

${ }^{6}$ Alejandro Sarbach Ferriol. ¿Qué pasa en la clase de filosofía? Hacia una didáctica narrativa y de investigación. Tesis doctoral, Departament de Didàctica i Organització Educativa, Facultat de Pedagogia, Universitat de Barcelona, p. 165.

7 Páez Casadiegos. Op. cit., p. 12.
} 
procedimientos?", . Y complementando esta referencia principal, encontramos a Philippe Meireu, quien se pregunta en qué consiste la obstinación de la didáctica:

¿Qué es lo que busca incansablemente si no es el alcanzar la capacidad de comprender las condiciones materiales y los mecanismos mentales gracias a los que un sujeto dado construye conocimientos determinados? [...] Su objetivo es instituir, en los lugares específicos destinados a los aprendizajes, un sistema de recursos y de obligaciones que represente las condiciones óptimas para aprender ${ }^{9}$.

Por tanto, el docente, quien tiene bajo su responsabilidad el diseño curricular de la asignatura, tendrá que decidir si el énfasis lo hace en la comprensión de los contenidos o en el desarrollo de los procedimientos gnoseológicos o hermenéuticos; también debe definir los recursos e identificar los lugares específicos para el aprendizaje; es su responsabilidad diseñar escenarios y ofrecer experiencias significativas propicias para el aprendizaje. Además, porque "se ha naturalizado la suposición según la cual: «quien sabe filosofía, sabe enseñar filosofía»"10. Y en ese sentido es que nos servimos del laberinto como escenario didáctico, aclarando que lo despojamos de toda la connotación trágica del mito original; aquí esperamos que los dioses no nos castiguen, ni que los reyes mueran por falta de una señal (aunque muchos docentes resultan "quemados"), ni que haya -mucho menossacrificios de jóvenes héroes aprendices de filosofía (aunque muchos estudiantes terminan en el mejor de los casos detestándola y reafirmando su supuesta inutilidad); y finalmente, tampoco se trata de buscar un monstruo tenebroso, deforme, cuyos bramidos nos espanten antes de terminar este ejercicio. Iniciemos el recorrido con la misma intención de Teseo de no morir en el intento.

\section{El escenario de la educación en filosofía}

Aebli -refiriéndose al aprendizaje autónomo- comenta con cierta ironía que las personas en general gustamos de aprender; los niños, particularmente, disfrutan aprendiendo; también nos gusta enseñar; lo complicado está en que coincidamos en tiempos y espacios. Es decir, que tanto quienes aprendemos como quienes enseñamos queramos hacerlo simultáneamente en el mismo lugar: en la escuela. Algo pasa, algo nos sucede para que en el aula (que no es solo un salón de clases) se pierda ese gusto por el conocimiento.

Pareciera que a medida que nos aproximamos al aula surge el laberinto; lo que teníamos claro en nuestras motivaciones e intenciones se pierde en medio del laberinto de la didáctica. Aquello que el docente planeó -cuando tiene tiempo para hacerlo- se pierde en los pasillos de la disposición de los estudiantes, de sus intereses vitales, de su misma actitud hacia la clase; pero a su vez, el asombro y la admiración de los estudiantes se pierde ante los pasadizos que elabora el docente con su discurso descontextualizado, sus tareas incomprensibles y extensas, su obsesión por mantenerlos a todos sentados y en silencio, y su inmenso poder evaluativo.

\footnotetext{
${ }^{8}$ Sarbach. Op. cit., p. 144.

${ }^{9}$ Philippe Meirieu. La opción de educar. Barcelona: Octaedro, 2001, p. 95.

${ }^{10}$ Germán Vargas. Filosofía, pedagogía, tecnología. 3. ${ }^{\text {ra }}$ edición. Bogotá: UPN, p. 18.
} 
En su tesis doctoral, Alejandro Sarbach Ferriol formula preguntas como: “¿Es realmente posible enseñar filosofía? ¿Es posible enseñar a pensar?" " “Cómo enseñar a filosofar mejor?"12 "¿Qué pasa en la clase de filosofía?"13. A los cuales podemos agregar: ¿Cómo intervienen los actores en el desarrollo de la clase? ¿Los intereses del docente logran hacer conexión con los de los estudiantes? ¿Por qué nos perdemos tan fácil en el desarrollo de las clases y del programa? ¿Acaso como docentes tenemos claro el objetivo de la enseñanza de la filosofía? Y por su parte, ¿los estudiantes tienen la posibilidad de explicitar sus metas de aprendizaje? En la práctica diaria pareciera que son dos minotauros distintos los que buscamos docentes y estudiantes.

A lo anterior se le puede agregar el predominio que en nuestro contexto social tienen a nivel profesional carreras relacionadas con las ingenierías, la economía, la administración, el diseño y los medios de comunicación, en relación con las humanidades y la filosofía. De alguna manera, el reto por posicionar la filosofía en el ejercicio pedagógico (a cualquier nivel escolar) no es algo que atañe exclusivamente a las situaciones didácticas, es también efecto de la tendencia social por lo pragmático e inmediatista, por lo efímero y placentero que en la cotidianidad riñe con el ejercicio crítico y hermenéutico propio de la filosofía.

En cuanto a la enseñanza de la filosofía, se encuentra con frecuencia la "conocida afirmación kantiana sobre la imposibilidad de enseñar filosofía, sino sólo a filosofar", en sus propias palabras:

Uno no puede aprender filosofía, sino únicamente a filosofar. La filosofía consiste precisamente en reconocer los propios límites. La filosofía es la ciencia de los límites de la razón». El mismo Kant dice en el lugar citado: la filosofía no se deja aprender... Una filosofía terminada ya no es filosofía, del mismo modo que un movimiento terminado ya no es movimiento. Enseñar filosofía es, pues, enseñar a preguntar y preguntarse filosóficamente ${ }^{14}$.

Siguiendo este planteamiento, entonces los currículos de filosofía deberían revisarse. Podríamos cuestionar el énfasis en la transmisión de datos sobre la historiografía Occidental de la filosofía que enseñamos, que traen los libros de textos y que nos llevan a trabajar didácticamente con nombres, fechas, obras y algunas ideas filosóficas de los pensadores más destacados. Lo cual dista mucho del objetivo kantiano, y el único límite que se reconoce es el del estudiante, quien se debe limitar a repetir nombres, fechas y postulados descontextualizados de su realidad.

Pero por otra parte, Javier de la Higuera también presenta la posibilidad de

...seguir defendiendo la primordialidad de los contenidos y de la filosofía como saber, aunque a costa, paradójicamente, de convertirlos en contenidos prefilosóficos de nuestra asignatura cuyo aprendizaje es mecánico (es la opción ejemplarmente representada por Hegel) [...] Hegel se enfrenta a la idea pedagógica de educar con vistas a pensar por sí mismo, idea que según él sólo conduce al vacío y a la impotencia intelectuales, a lo arbitrario y a lo fantástico [...]. Para Hegel, la filosofía es una ciencia

\footnotetext{
${ }^{11}$ Sarbach. Op. cit., p. 26.

12 Ibídem, p. 27.

${ }^{13}$ Ibídem, p. 30.

${ }^{14}$ Tejedor, citado por Sarbach, Op. cit., p. 145.
} 
ya existente, un bien que el profesor posee y que puede ser transmitido y, por tanto, aprendido. Es necesario, pues, comenzar por un contenido ${ }^{15}$.

Nos encontramos así con argumentos y contraargumentos que suscitan el debate y ejemplifican el laberinto con posibles caminos que parecen prometedores, pero hasta no recorrerlos en su totalidad no es posible identificar si en realidad conducen al objetivo deseado. De hecho, una tercera posición se puede encontrar en el planteamiento del profesor Terricabras:

...seguramente no es posible enseñar a pensar [...], únicamente es posible aprender a pensar [...]. Esta perspectiva nos conduce a una situación aporética respecto del enseñar y el aprender: el alumno debe aprender algo que no es posible enseñar. Aporía relacionada con otra ya planteada en el Menón: si ya conocemos algo no es necesario aprenderlo, y si no lo conocemos no es posible aprenderlo precisamente porque no sabemos lo que tenemos que aprender ${ }^{16}$.

Sin la intención de agotar diagnósticos que todos conocemos, porque los vivimos como docentes de la asignatura, la propuesta didáctica que se plantea a continuación se centra en el docente, como el agente responsable inicialmente de tomar las decisiones pedagógicas y didácticas que marcan el desarrollo de cualquier curso de filosofía.

\section{El docente de filosofía}

A los anteriores planteamientos sobre la posibilidad misma de la enseñanza de la filosofía o del filosofar se le puede agregar el hecho de que la filosofía depende del maestro que a uno le toque, así lo comenta Sarbach:

Con frecuencia, cuando los alumnos hablan de la asignatura de filosofía dicen muchas cosas: es una asignatura muy difícil, demasiado abstracta, aburrida, difícil de aprobar, apasionante, que te obliga a pensar... Sin embargo, también se puede reparar en una observación recurrente y muy generalizada: "depende del profesor que te toque"..., pareciera que la dependencia discursiva se da en un grado mayor de la que pudiera darse en otras asignaturas ${ }^{17}$.

Insisto entonces en la importancia de concentrarnos en la responsabilidad didáctica del docente, ya que es él quien en un primer momento toma las decisiones didácticas sobre su curso. Así que sin devolvernos a los orígenes, propongo mirar solo tres hebras de su hilo de Ariadna para entrar a ese laberinto que es el ejercicio pedagógico filosófico; dichas hebras se pueden mencionar así: 1) su propia experiencia, 2) sus concepciones y 3) su ejercicio reflexivo sobre su praxis.

\section{La experiencia personal del docente}

En primer lugar, la experiencia personal del docente es un elemento determinante en la forma como al menos se empieza a enseñar, ya que todas las personas solo hacen aquello

\footnotetext{
${ }^{15}$ Sarbach. Op. cit., p. 146.

${ }^{16}$ Ibídem, p. 155.

${ }^{17}$ Ibídem, p. 160.
} 
que saben. Por tanto, como docentes de filosofía intentamos enseñarla como la hemos aprendido. Nuestra experiencia como dicentes es una huella que nos marca. Alejandro Sarbach señala la incidencia que tiene la "trayectoria biográfica", es decir, la manera como ha sido formado el docente y su posterior "posición estructural" en la identidad del profesor de filosofía; y lo explica así:

Según nuestra identidad, aquella que resulta de nuestra historia y de nuestras inserciones presentes, generaremos una asignatura de filosofía determinada. Pero también podemos proponer la formulación inversa: aquel conjunto de peculiaridades propias de nuestra clase de filosofía nos construye y nos retorna una determinada identidad que se refleja como las imágenes infinitas de un espejo... ${ }^{18}$.

Al respecto, Germán Vargas trae a colación la frase de Ficthe:

"que cada clase de filosofía le gusta a uno, depende de la clase de persona que se es"... con poca frecuencia nos preguntamos por qué nosotros mismos, como profesionales tanto de la filosofía como de su enseñanza, nos sentimos más cómodos cuando tratamos con un determinado enfoque, con respecto a una tradición definida, que en otros temas, enfoques y tradiciones ${ }^{19}$.

Producto de esa biografía, todos los profesores tenemos algún autor con el cual nos identificamos más; hay un tratado con el cual nos sentimos más cómodos que con otros y lo mismo sucede con las escuelas filosóficas. Nuestra biografía no está ajena de nuestra praxis pedagógica. Hacemos lo que sabemos y lo hacemos con base en unas voliciones que hemos ido incluyendo en nuestro ejercicio cotidiano de forma poco clara, casi irreflexiva (en casa de herrero, azadón de palo). Entonces valdría la pena que cada uno de nosotros identificara sus huellas formativas: ¿qué le marcó más en su proceso como estudiante de filosofía?; ¿cuáles son sus preferencias temáticas?; ¿hay algún filósofo favorito al cual se ha acercado más, ya sea conociendo mejor sus obras y su contexto histórico?; ¿se identifica de alguna manera con un determinado periodo histórico o con las características filosóficas de un contexto cultural específico?

Este es un trabajo diacrónico que remite a nuestro pasado, a nuestra experiencia personal, en el cual es necesario tener en cuenta tanto aspectos conceptuales como aspectos socioafectivos, ya que la identificación resultante no es un producto exclusivamente cognitivo, sino que es resultado de esas conexiones entre unas ideas con reconocimiento históricocultural y nuestras preferencias personales. El valor didáctico de la experiencia docente es que, una vez reconocida, el docente puede empezar a construir de manera más sólida su estructura de pensamiento, elaborar sus concepciones, tiene ya una hebra que sirve de hilo conductor para contar "su cuento", para desinstalarse de lo que Martens llama una "didáctica-copia", que solo conduce a "dinámicas ajenas, como enajenadas"20.

Finalmente, este aspecto biográfico no es exclusivo del docente, ya que "en la construcción de la asignatura participa una red de significados y de acciones, provenientes de los

\footnotetext{
${ }^{18}$ Ibídem, p. 162.

${ }^{19}$ Germán Vargas. Op. cit., p. 18.

${ }^{20}$ Sarbach. Op. cit., p. 162.
} 
profesores y de los alumnos, de sus historias pasadas y de sus interrelaciones presentes",21, así que las historias personales de los alumnos también empiezan a verse afectadas por lo que sucede en el espacio académico.

\section{Las concepciones del docente}

La segunda hebra representa las concepciones del docente, es decir, las construcciones propias, los logros o hallazgos personales que le han permitido a cada docente organizar su "andamiaje" de conocimientos. En el ejercicio de la enseñanza de filosofía es inevitable caer en la dinámica de la pregunta; así nos esforcemos por ser total "dictadores" de clase, afortunadamente siempre hay estudiantes que nos liberan de ese yugo y formulan preguntas inteligentes, sugerentes, que abren el diálogo, que motivan el debate, que invitan a los demás a participar en la respuesta. Como lo afirma Sarbach:

Pareciera que la filosofía es aquella asignatura que se caracteriza por que su contenido ofrece las herramientas, tanto a profesores como a alumnos, para que se produzca el cuestionamiento de sus formas de transmisión. El desarrollo de la asignatura se dibuja, diría irremediablemente, en un horizonte de crisis ${ }^{22}$.

Cuando esto sucede en clase, entonces, ya no es pertinente seguir con el mapa conceptual en el tablero, ni continuar con la lectura del texto, ni avanzar en la exposición; es necesario recurrir a lo que estoy llamando nuestro "andamiaje" conceptual, a esas elaboraciones cognitivas que a lo largo de nuestro proceso formativo y profesional hemos construido. Ya sea, al menos por el gusto o afinidad de la cual hablábamos anteriormente.

Esas concepciones personales implican un ejercicio filosófico de nivel superior a la identificación de la afinidad con unos elementos teóricos, y en ese sentido sería de gran valor que el docente empezara a escribir sobre sus propias concepciones. Además, por el inmenso valor didáctico que tiene en general el modelaje del profesor, aún en tareas de tipo más pragmático; ya que con frecuencia los docentes solicitamos a los estudiantes que hagan trabajos que a nosotros mismos nos generan gran dificultad. El caso más representativo es cuando les pedimos a los estudiantes que elaboren un ensayo, pero nosotros mismos no hemos hecho el ejercicio.

Los beneficios del ejercicio escritural no se limitan a las acciones más operativas, sino que se relacionan con el desarrollo mismo de nuestras habilidades de pensamiento, sólo a modo de sugerencia menciono la importancia que tiene la relación pensamiento-lenguaje y en ella las bondades de ejercitarse en la producción escrita. Nuestros estudiantes deberían tener la oportunidad de leer nuestros ensayos, nuestras disertaciones, por qué no los artículos que hemos publicado, así nuestras concepciones no son únicamente flautus voicis (sonidos de la voz) sino que se concretan documentalmente como evidencia de nuestro ejercicio filosófico y modelaje de nuestra didáctica filosófica.

\section{La reflexión sobre la praxis}

\footnotetext{
${ }^{21}$ Ibídem, p. 163.

${ }^{22}$ Ibídem.
} 
En tercer lugar está el elemento que, a mi modo de ver, es el más importante: la reflexión del docente sobre su praxis. En esta fina hebra se conjugan tanto los elementos filosóficos más teóricos como los elementos didácticos. Si aceptamos que la filosofía no es sólo su contenido y desarrollo histórico, sino también una actitud crítica, indagadora, hermenéutica de la experiencia humana, entonces el docente de filosofía no puede ser ajeno a realizar sus ejercicios reflexivos y analíticos, pero la materia de indagación no pueden ser solamente los asuntos filosóficos, sino también sus asuntos pedagógicos.

Todos nosotros compartimos la experiencia -cada vez más agotadora- de no tener tiempo, mucho menos para planear como quisiéramos nuestras clases, y una vez terminadas las sesiones semanales sentimos cómo al cúmulo de asuntos pendientes se suman otros tantos. Entonces ¿a qué hora vamos a reflexionar siquiera sobre lo que hemos hecho? Pero el problema no se puede limitar a un aspecto secundario de horarios, la reflexión rigurosa sobre nuestra praxis en la clase de filosofía es tal vez la hebra más resistente que nos puede llevar con éxito a la salida del laberinto didáctico.

Siguiendo a Sarbach, la pregunta, además de ser el motor que permite la búsqueda de nuevos saberes, también es clave para "desentrañar el significado de los ya conseguidos",23; y la práctica pedagógica del docente es también un saber, de tipo pragmático, cuyos significados debemos desentrañar. Respecto a la práctica, Lia Sañudo insiste en su valor epistemológico:

El "significado" no implica aquella "teoría" que en cierto modo es externa al sujeto que concibe su práctica, sino a sus específicos supuestos, saberes, creencias, valores y prefiguraciones de los haceres, en este caso referidos a los procesos educativos. De manera que dependiendo de cómo el educador "signifique" su práctica es así como la realiza ${ }^{24}$.

Con este ejercicio, de por sí filosófico, podemos entrelazar muy bien las otras dos hebras: la de la experiencia y la del andamiaje conceptual, y de esa manera conformar un trenza que ofrece como resultado un aprendizaje armónico, como el que se desea también logren los estudiantes. Y nos referimos a un aprendizaje en tanto que se conjugan aspectos cognitivos (en lo que hace relación al andamiaje), procedimentales (en lo que hace relación a la experiencia) y actitudinales (en lo que hace relación a la permanente reflexión sobre la praxis).

Tal vez todos podríamos coincidir en aceptar que la enseñanza de la filosofía tiene dentro de sus fines la construcción de un pensamiento de orden superior, lo cual vuelvo a identificar como aprendizaje armónico de la filosofía. En lugar del horroroso minotauro, el laberinto nos esconde ese aprendizaje armónico, no solo de los estudiantes, sino también de nosotros como docentes. De esa manera ya no hablaríamos de dos monstruos, sino de un propósito común.

\footnotetext{
${ }^{23}$ Ibídem, p. 177.

24 L. Sañudo de Grandre. "El proceso de significación de la práctica como un sistema complejo" en: R. Perales (coord.): El significado de la práctica educativa. México D.F.: Paidós, 2006. p. 20.
} 


\section{La didáctica como práctica}

El anterior planteamiento, como muchos otros, en principio puede asumirse en el plano propositivo como algo válido. Pero el reto está en la cotidianidad del aula, ¿cómo hacerlo? Y en ese sentido nos centramos en el núcleo de la naturaleza didáctica que es la práctica. Por eso la pregunta tiene total validez, no tanto para buscar recetas y fórmulas que luego atentarán contra el mismo ejercicio pedagógico, sino para cuestionar permanente la praxis, aun desde la praxis misma.

Para este último apartado, reconozco que el laberinto se torna más confuso y enredado, si se quiere. Pero continuemos desenvolviendo nuestro hilo, con sus tres hebras. La intención es mostrar aquí las interacciones entre docentes y estudiantes para que entre juntos podamos alcanzar ese propósito del aprendizaje armónico en filosofía. Con esto estamos afirmando que, sin duda, la filosofía es objeto de enseñanza y aprendizaje, tanto en sus desarrollos históricos y culturales como en la actitud filosófica que se espera desarrollen todos quienes se acercan con amor al conocimiento.

Desde finales del siglo pasado las reformas curriculares, principalmente en el contexto de la enseñanza básica, se han orientado a favorecer que el aprendizaje no se quede únicamente en los elementos conceptuales, en lo cual la escuela había hecho énfasis. Entonces se consideró pertinente promover también elementos procedimentales y actitudinales para lograr un mejor aprendizaje. Con base en este trinomio, vamos a presentar algunas pistas tanto para docentes como para estudiantes, con cierto paralelismo, a fin de evitar que los unos y los otros sigan cada uno por su lado tratando de encontrar una salida a ese laberinto en que se convierte el salón de clases.

\section{Aspectos conceptuales}

Es claro que el conocimiento filosófico ha venido desarrollando un corpus, del cual forman parte los pensadores que históricamente reconocemos por la originalidad de sus ideas, por los aportes y la producción que ha permanecido a través del tiempo y de los distintos contextos culturales. "Es obvio que cuando se piensa en enseñar, se piense necesariamente en algo que enseñar; sin embargo, no parece tan obvio que cuando se piensa en la Filosofía como conjunto de saberes necesariamente se piense en su transmisión”,25.

En cuanto a los aspectos conceptuales, al docente le compete tener en cuenta en su didáctica, al menos, tres fines: 1) contextualizar histórica y culturalmente los hechos y las características en las cuales surgieron las ideas filosóficas, 2) elaborar una mirada de conjunto respecto al desarrollo y a las relaciones entre escuelas, posturas y movimientos filosóficos, y 3) plantear problemas que permitan a los estudiantes acercarse al corpus filosófico de manera activa. El profesor Bondy encuentra que la enseñanza de la filosofía se justifica, entre otras razones, porque "la filosofía completa el cuadro de la cultura que debe adquirir el educando de secundaria y tiende a darle una visión integrada, totalizante y no meramente aditiva, de los diversos sectores del conocimiento y la creación humana"; además, porque:

\footnotetext{
${ }^{25}$ Sarbach. Op. cit., p. 141.
} 
El conocimiento, las creencias, los valores y autoridades con que es confrontado el educando a lo largo de su educación no han sido sometidos sistemáticamente al imperio de una reflexión crítica que ponga por encima de toda norma la racionalidad y la verdad universal [...]. La reflexión y la orientación filosóficas contribuyen decisivamente a enmendar estos defectos. ${ }^{26}$

No podemos renunciar al fin humanista que tiene la enseñanza de la filosofía, lo cual implica hacer "hincapié en la función y el sentido del hombre, con lo cual el maestro contribuye decisivamente" 27 . Sus elecciones didácticas sin duda marcan la experiencia filosófica de sus estudiantes. En este punto, por ejemplo, la selección del texto, su uso dentro y fuera del aula, la forma como se presentarán los filósofos, sus ideas, su contexto cultural; las relaciones con pensadores o escuelas de pensamiento anteriores y posteriores, y sobre todo los problemas que abordaron son decisiones didácticas importantes.

Por su parte los estudiantes estarían invitados a: 1) realizar conexiones entre las distintas épocas históricas, reconociendo las características más propias de cada una de ellas y los distintos fenómenos que dieron paso a cambios significativos en el desarrollo de las ideas; 2) sintetizar los planteamientos filosóficos de los distintos autores o escuelas de pensamiento; y 3) ofrecer respuestas, desde su perspectiva actual, a los problemas que se plantearon los distintos pensadores, en el marco de un proceso investigativo, ya que "el alumno tiene la posibilidad de recorrer el proceso investigador, para comprender la génesis del conocimiento científico, pero, sobre todo, asumir su carácter provisional, y la importancia del error en su progreso" 28 .

\section{Aspectos procesales}

Para poder realizar ese amplio cuerpo teórico que hoy reconocemos como filosofía, ha sido necesario que en los distintos momentos cada filósofo haya trabajado de manera metódica, identificando con rigor un determinado proceso de pensamiento.

En cuanto a los aspectos procesales, al docente le compete: 1) Suscitar preguntas lícitas, con valor filosófico, relacionadas con el contexto propio de los estudiantes; 2) Dejarse cuestionar como un participante más dentro de la dinámica del aula, y 3) contar su cuento de manera convincente y como fruto de esa apropiación conceptual que ha venido realizando.

Respecto al valor y la importancia de las preguntas, se encuentra amplia referencia en la propuesta de filosofía para niños de Lipman. Infortunadamente -siguiendo a Sarbach- la pregunta en la clase de filosofía se presenta:

...habitualmente como "falsa pregunta" o como "no pregunta", como pregunta que en su formulación ya presupone la respuesta, como pregunta retórica. Cabe advertir que somos los profesores los que solemos ocupar el espacio de la clase con este tipo

26 A. Bondy S. Didáctica de la filosofía, p. 30. [en línea]. Disponible en: http://sisbib.unmsm.edu.pe/exposiciones/Salazar_bondy/publicaciones/didactica_filosofia/indice_didactica.ht $\mathrm{m}$.

${ }^{27}$ Ibídem, p. 40.

${ }^{28}$ Sarbach. Op. cit., p. 124. 
de preguntas [...] una didáctica basada en las preguntas, más que en las respuestas, tendría dos implicaciones fundamentales: se aseguraría una comprensión mucho más ajustada del pensamiento de los autores, y permitiría identificar los problemas y traducirlos en preguntas adecuadas ${ }^{29}$.

Con base en esta última afirmación, entonces pasamos al segundo elemento mencionado anteriormente, es decir, que el profesor se deje interrogar, que participe de ese "laboratorio gnoseológico", ofreciendo sus respuestas como un insumo más de la clase, para ser evaluadas por todos los demás. El profesor no es el único que puede formular preguntas, de hecho debe suscitarlas, como también debe motivar el cuestionamiento respecto a sus afirmaciones y respuestas. Referirse a la clase como un laboratorio es establecer una dinámica de búsqueda de los mejores argumentos, de las mejores razones como resultado de un ejercicio colectivo de aprendizaje alrededor de problemas significativos.

La propuesta de la clase de filosofía entendida como laboratorio de simulación de la actividad filosófica (desarrollada por Izuzquiza) puede resumir en los siguientes aspectos:

- La clase se construye como laboratorio conceptual (participación activa y creativa de los alumnos).

- En este laboratorio conceptual se simulan operaciones conceptuales, o el comportamiento conceptual del tratamiento de determinados problemas.

- La materia de investigación son los problemas filosóficos, que deben ser traducidos, es decir, su explicitación adecuada al discurso de los alumnos ${ }^{30}$.

Finalmente, vamos a referirnos a lo que se ha denominado "contar su cuento"; con esta expresión se quiere hacer referencia a un elemento didáctico de carácter narrativo, como alternativa a la tradicional exposición magistral.

Siguiendo a Lipman, aquello que diferencia un texto narrativo de uno expositivo son tres características: las narraciones son dinámicas, son abiertas y están narradas en primera persona. Que sean dinámicas significa que exponen un desarrollo, un transcurrir de sucesos encadenados, que abren un mundo en movimiento, en permanente cambio. Que sean abiertas quiere decir que no son conclusivas, que no hay ideas terminadas ni conclusiones definitivas, todo puede ser revisable; el suspenso, la intriga, la curiosidad, son sus rasgos dominantes; siempre nos invitan a continuar, siempre nos dejan con las ganas de que no acaben. (Es en aquellas pocas ocasiones que algún alumno pregunta asombrado: “ya se terminó la clase?”). Pero quizá, el rasgo definitivo, y también la exigencia más difícil de conseguir, sea la narración en primera persona ${ }^{31}$.

Entonces, se pueden relacionar las concepciones que el profesor va construyendo fruto de su experticia con esta estrategia narrativa, ya que el cuento del profesor bien puede estar constituido en buena medida por dichas concepciones, dando lugar a una espiral cognitiva

\footnotetext{
${ }^{29}$ Ibídem, p. 177.

${ }^{30}$ Ibídem, p. 149.

${ }^{31}$ Ibídem, p. 120.
} 
en el docente, ya que el ejercicio mismo de contar su cuento enriquece sus concepciones y viceversa.

Por su parte, los estudiantes estarían invitados a: 1) vincular las preguntas que se generan en la clase con su contexto cotidiano; 2) participar de la dinámica dialógica propia de la filosofía; y 3) asumir una posición crítica (ante el docente), como lo enuncia Bondy: "El problematismo, la actitud crítica, la capacidad de iluminación de la totalidad de lo existente y del sentido del mundo que aspira toda enseñanza filosófica no pueden estar ausentes de la"32 enseñanza filosófica, es lo que él llama finalidad "formativa o de cultivo del espíritu del" estudiante.

\section{Aspectos actitudinales}

El giro de la didáctica filosófica tiene aquí su eje, en tanto que se insiste en el planteamiento kantiano de enseñar a filosofar, más que enseñar filosofía; lo único que se puede hacer es promover esa actitud filosófica en los estudiantes. Particularmente considero que sería de mayor valor didáctico el logro de una síntesis armónica entre el conocimiento y dominio del corpus filosófico y el desarrollo de la competencia filosófica.

En cuanto a los aspectos actitudinales, al docente le compete: 1) valorar la indagación filosófica comunitaria; y 2) reflexionar permanentemente sobre su praxis filosófica. En lo relacionado con la indagación comunitaria se encuentra "la propuesta de construir una 'comunidad de investigación' en el aula (E. Lipman, 1980, 1991: programa Philosophy for childrens, 'Filosofia 6-18' en Catalunya) y el trabajo de investigación filosófica mediante una didáctica no expositiva y que contenga materiales y estilos narrativos"33; el énfasis no está en las explicaciones ni en los discursos del docente, sino en lo que Sarbach llama los estilos narrativos a los cuales ya nos referimos.

El "pensamiento de orden superior" (Lipman, 1991) integra dos dimensiones de la actividad intelectual humana: la inteligencia crítica y las potencialidades creativas. Dos dimensiones que pueden relacionarse con los aspectos fundamentales de la propuesta Philosophy for childrens: la utilización de textos narrativos y la construcción de comunidades de investigación filosófica en el aula. Tanto el carácter narrativo de mucho de los textos utilizados, como la dinámica de investigación impulsada en la clase, tienen el común denominador de la mediación crítica respecto de aquellas prácticas expositivas y academicistas que, aunque con frecuencia inevitables, suelen obturar la expresión del pensamiento de los alumnos y, en consecuencia, la reflexión crítica y creativa sobre su contenido ${ }^{34}$.

La comunidad de indagación es una alternativa consolidada que permite entre otros beneficios evitar que la enseñanza de la filosofía se convierta en un determinado tipo de adoctrinamiento o proselitismo político; que termine siendo un curso de retórica "es decir, adiestramiento deliberado y sistemático en técnicas de persuasión, con olvido de la substancia del pensar filosófico que es la búsqueda de la verdad racionalmente fundada"35;

\footnotetext{
32 Bondy. Op. cit., p. 38.

${ }^{33}$ Sarbach. Op. cit., p. 33.

${ }^{34}$ Ibídem, pp. 113-114.

${ }^{35}$ Bondy. Op. cit. , p. 42.
} 
que se quede en un escenario abstracto sin relación alguna con la cotidianidad del alumno, ni con su realidad social y cultural, y finalmente evita que la clase de filosofía se vuelva una especie de anecdotario personal del profesor $^{36}$.

Por su parte, los estudiantes estarían invitados a: 1) conformar colectivamente la comunidad de indagación; y 2) desarrollar un pensamiento de orden superior como fruto de su actitud reflexiva y crítica. Como lo describe Bondy al referirse al método socrático: "Se trata de llevar al sujeto filosofante a un comienzo absoluto, a un punto en el cual no habrá de necesitar el apoyo de las convicciones previamente adquiridas y a partir del cual podrá progresar libremente en el saber",37.

En cuanto al pensamiento de orden superior, Sarbach argumenta -refiriéndose a Lipman-: "la finalidad de la enseñanza de la filosofía, acometido realizable por cierto desde la más temprana infancia, tiene por finalidad desarrollar un 'pensamiento de orden superior'; y el instrumento adecuado para ello es la construcción en el aula de una 'comunidad de investigación filosófica,,38. En otro apartado, Sarbach insiste en que: "priorizar la enseñanza de la filosofía como actividad, respecto de la transmisión académica de contenidos, nos lleva necesariamente a proponer como meta central del trabajo en la clase el desarrollo del pensamiento creativo",39.

\section{A modo de conclusión: buscando al alumno}

Todo lo que se ha planteado anteriormente tiene sentido y validez en tanto que la intención del docente, como fuerza volitiva en aras de un objetivo mayor, esté orientada -con profunda honestidad- hacia el estudiante. Tenemos el riesgo de perdernos en el laberinto de nuestras innovaciones didácticas si el propósito no es el estudiante; el hilo de Ariadna nos debe invitar a recorrer otros pasadizos, distintos a los que ya recorrimos cuando éramos estudiantes. Así que el reto será primero desaprender, para introducir cambios significativos en nuestra praxis y enseñar de manera diferente a como hemos aprendido.

Lo anterior implica que el centro sea el estudiante, que la actividad principal sea aprender, que el vínculo fundamental entre estudiante y profesor sea en aras de mantener una permanente dinámica de construcción cognitiva. Entonces, el programa, los contenidos, la evaluación, los recursos han de estar girando alrededor del estudiante, como lo propone Foulquié al referirse a los principios generales de una nueva didáctica; sugiere que prime la educación sobre la instrucción, que las ciencias de la educación se sirvan de otras ciencias para comprender mejor el fenómeno del aprendizaje, por lo tanto, que la educación se enfoque en el estudiante, "una educación individual en espíritu comunitario" en el cual se encuentre inmerso también el profesor ${ }^{40}$.

\footnotetext{
${ }^{36}$ Cfr. Bondy. Op. cit., pp.: 41-43.

${ }^{37}$ Bondy. Op. cit., p. 120.

${ }^{38}$ Sarbach. Op. cit., p. 123.

${ }^{39}$ Ibídem, p. 152.

${ }^{40}$ P. Gasparotto. Notas de didáctica filosófica. México: Universidad Pontificia de México, 2000. pp. 11-12.
} 
En la actualidad el reto de la didáctica se puede concretar en cuatro fines: conocer, practicar, valorar y participar. La filosofía, como asignatura de una propuesta curricular, ha sido partícipe del énfasis que ha hecho el sistema educativo en el conocer, dejando de lado las otras tres metas. Desde la didáctica es vital que la filosofía promueva la práctica, la valoración y la participación en los estudiantes. Considero que las breves pistas aquí ofrecidas están orientadas a dichos fines.

Bien, con la intención de dejar solo unos puntos suspensivos que permitan posteriores diálogos, quisiera compartir que mi recorrido por este laberinto me ha permitido reconocer en los discursos del personalismo y de la ética mis principales puntos de referencia dentro del corpus filosófico; si se trata de autores, entonces he de remitirme a Mounier y a Levinás, aceptando que debería conocerlos de manera más cercana y familiar.

De algunas experiencias formativas me ha quedado el gusto por indagar y explorar más de cerca los trabajos sobre filosofía para niños, formación ética y pedagogía del cuidado; considero que entre estos dos enfoques hay muchos puntos en común que pueden potenciar nuevas prácticas pedagógicas respecto a la enseñabilidad de la filosofía. Reconozco también que mi discurso oral es mayor a mi discurso escrito, pero me he venido esforzando por lograr un menor desequilibrio.

Finalmente, soy un convencido respecto al valor de la reflexión sobre la praxis pedagógica, me esfuerzo por realizarla con seriedad, por ubicar algún elemento específico para modificarla y estar atento a los posibles efectos del cambio. La retroalimentación de los estudiantes es muy valiosa, pero no dejo de lado la autocrítica y la exigencia por no caer en ejercicios didácticos insípidos o diluidos.

Más que ser ejemplo de un buen modelaje de enseñanza, sigo intentando ser un aprendiz, y desde esta experiencia construir una experticia que tenga algún significado en momentos como estos, cuando me atrevo a compartirla en voz alta, más con el propósito de retroalimentarla con las voces de mis colegas.

Estas hebras me han permitido moverme con cierta agilidad por el laberinto de mi ejercicio didáctico, pero también han generado la incertidumbre al reconocer que no hay recetas ni fórmulas secretas. Mi hilo de Ariadna hoy me ha permitido llegar a este momentáneo solaz para seguir aprendiendo. 


\section{Bibliografía}

Bondy S., A. Didáctica de la filosofía. [En línea] Disponible en: http://sisbib.unmsm.edu.pe/exposiciones/Salazar_bondy/publicaciones/didactica_filos ofia/indice_didactica.htm. 332 p.

Gasparotto, P. Notas de didáctica filosófica. México: Universidad Pontifica de México, $2000.523 \mathrm{p}$.

LIPMAN, M.; Sharp, A.; Oscayan, F. La filosofía en el aula. Madrid: Ediciones de la Torre, 2002, $380 \mathrm{p}$.

MEIRIEU, Ph. La opción de educar. Barcelona: Octaedro, 2001, 219 p.

PÁEz CASAdiEgos, Y. "El minotauro en su laberinto". Aposta. Revista de ciencias sociales n. ${ }^{\circ}$ 3. Obra finalista en el 1. ${ }^{\text {er }}$ Certamen de Ensayo Filosófico del Ciberespacio, 2003, $34 \mathrm{p}$.

SAÑUDO DE GRANDRE, L. "El proceso de significación de la práctica como un sistema complejo". En: R. Perales (coord.): El significado de la práctica educativa. México: Paidós, 2006, pp. 19-54.

SARBACH Ferriol, A. ¿Qué pasa en la clase de filosofía? Hacia una didáctica narrativa y de investigación. Tesis doctoral, Departament de Didàctica i Organització Educativa, Facultat de Pedagogia, Universitat de Barcelona, 2005, 646 p. [En línea] Disponible en: http://www.tesisenxarxa.net/TDX-0426106-160909/index.html

TEJEDOR CAMPOMANES, C. Didáctica de la filosofía, perspectivas y materiales. Madrid: SM Ediciones, 1984.

VARGAS, G. Filosofía, pedagogía, tecnología. 3. ${ }^{\text {ra }}$ edición. Bogotá: UPN. 